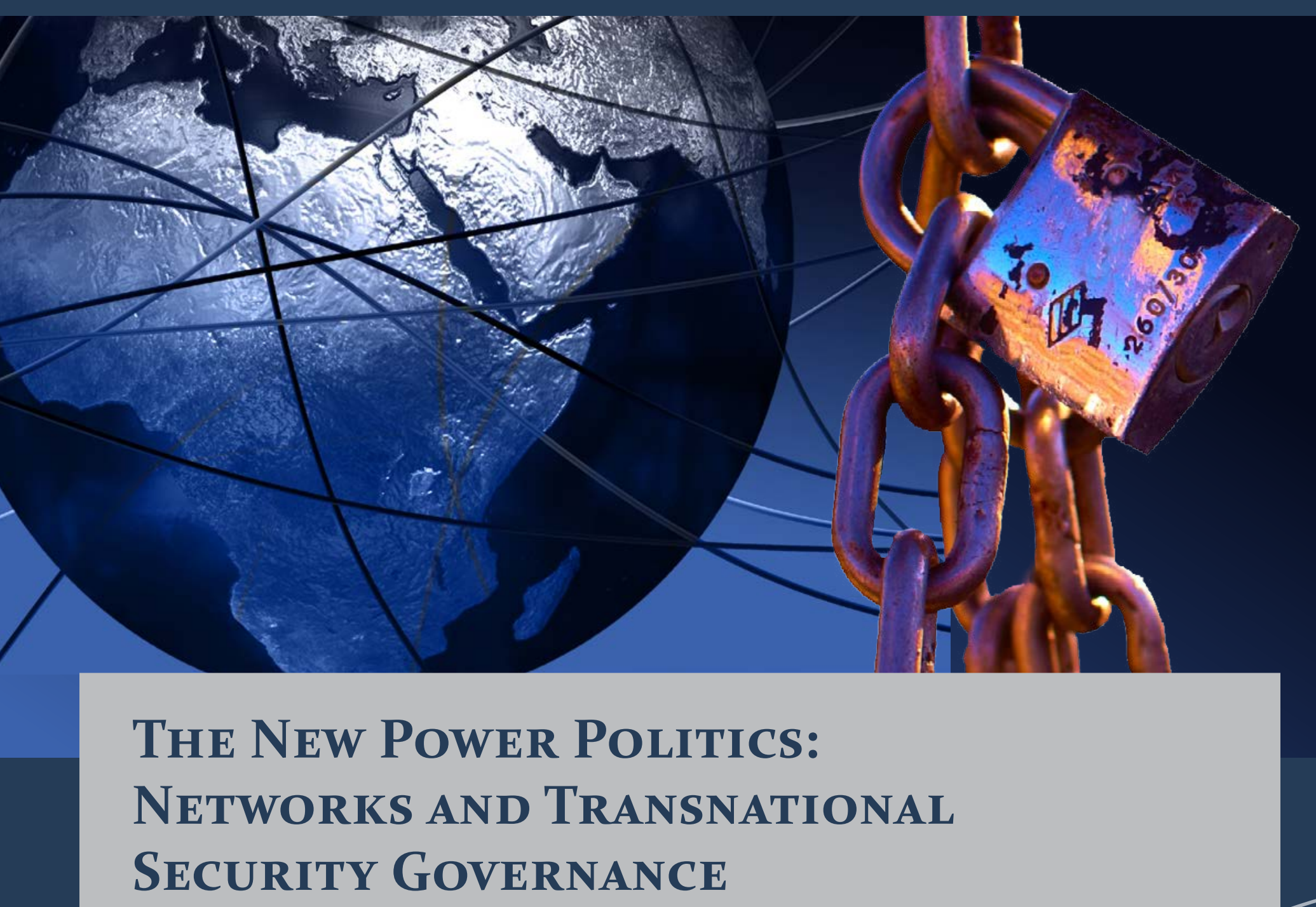




\section{The New Power Politics: \\ NETWORKS AND TRANSNATIONAL SECURITY GOVERNANCE}

The workshop series "The New Power Politics: Networks,

Governance, and Global Security" examined how various networks of state and non-state actors work to address the governance of security. Participants included internationally recognized scholars who research a wide range of contemporary security issues.

In March 2013 the second part of the workshop was held at the Sie Chéou-Kang Center at the University of Denver. Workshops were led by Deborah Avant, Sié Chair and Director of the Sié ChéouKang Center, and Oliver Westerwinter, lecturer at the European University Institute. Support was provided by One Earth Future Foundation.

The conference report on this workshop is authored by Deborah Avant, Sié Chair and Director of the Sié Chéou-Kang Center, and Lindsay Heger, Research Associate at One Earth Future Foundation. 


\section{The New Power Politics: Networks and Transnational Security GOVERNANCE}

During the spring of 2013, the Sié Chéou-Kang Chair for International Security and Diplomacy at the University of Denver's Josef Korbel School of International Studies, with support from the One Earth Future Foundation, organized a group of researchers to discuss how network theory can shed light on the governance of security issues. This memo highlights insights from this gathering relevant for practitioners designing or participating in security governance. In-text author citations refer to project abstracts, which are all listed at the end of the memo.

Contemporary discourse frequently focuses on the relevance of nonstate actors' contributions to (and participation in) systems of governance. From exploring how nongovernmental organizations (NGOs) make contributions in war zones and failed states to the role international organizations play in facilitating meaningful exchange between nations, the discourse widely acknowledges a modern truism: governance is no longer the exclusive province of states. Another descriptor that is increasingly common in discussions of governance arrangements is networks. We speak frequently of advocacy networks, epistemic networks, and governance networks. Indeed, much of the governance that goes on in today's world is accomplished by various networks including some combination of national bureaucrats, intergovernmental organizations (IGOs), NGOs, transnational corporations, business associations, and civil society organizations. Though they come in many shapes and sizes, these new networks of governing are crucial parts of global and local politics. This memo highlights insights from leading analysts using network theory to understand how states and nonstate actors together contribute to governance outcomes in security issues.

\section{Some Definitions}

The core essence of governance is steering a collective - shaping expectations, generating collective action (including the provision of "public goods," here defined as goods that are nonexcludable and nonrivalrous in consumption; see Avant et al. ${ }^{1}$ for more information), and otherwise "ordering" a group. The governance process involves a variety of different tasks: setting agendas, making rules, implementing and overseeing policy, enforcing rules, and adjudicating conflicts over rules.

Security refers to those issues that actors worry about as threats and mobilize collective resources around (Buzan 1991) $)^{2}$. The analysts who gathered for this workshop focused on an array of contemporary security challenges. Some examined power politics and the management of violence familiar to traditional views on security (e.g., Heger, Jung, and Wong; Kinsella; Kenney, Coulthart, and Martin; Murdie, Bell, Blocksome, and Brown). Others explored human security or broader efforts to shape global outcomes in ways that manage conflict and avoid the use of violence (e.g., Avant, Carpenter, Jakobi, Westerwinter).

Networks are sets of actors (nodes) connected (or not) by links. Connections between actors (e.g., line $\mathrm{X}$ connecting actors A and B in Figure 1) indicate the presence of a relationship. Actors unlinked (e.g., $\mathrm{A}$ and $\mathrm{C}$ in Figure 1) do not have a relationship.

3 | The New Power Politics: Networks and Transnational Security Governance 


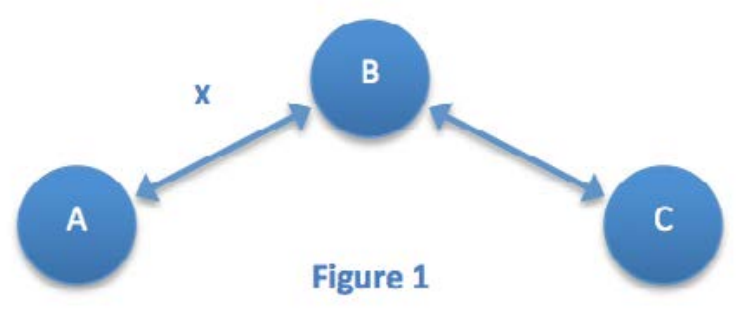

\section{How Do Governance Outcomes and Networks Vary?}

Contemporary systems of transnational governance often link actors as diverse as international organizations, NGOs, state bureaucracies, and private enterprises. The Kimberley Process - an effort to prevent profits from the international diamond market from driving civil wars in Africa-is one example. It linked states, private industry, and human rights NGOs in a network to implement a system for certifying processes whereby buyers could distinguish conflict diamonds from those mined in ways that did not contribute to conflict (Westerwinter).

But not all governance outcomes are like the Kimberley Process. The workshop looked particularly at three ways that governance outcomes can vary (Avant and Westerwinter). They can be more or less effective. The Kimberley Process can be characterized as a relatively effective governance outcome because it has reduced the flow of conflict diamonds. Less effective outcomes include, for example, attempts to regulate small arms that have had little impact on the global flow of these weapons. Governance can also vary by whom it serves. Additionally, some governance outcomes serve a select few while others serve the general collective interest. Consider, for example, multistakeholder cooperative efforts concerning climate change that are frequently intended to realize global benefits versus governance outcomes that are associated with natural disasters and thus serve a more local population. Some outcomes may also act at a global level but in a way that serves the interests of only a few. Many have alleged that the Trade Related Aspects of Intellectual Property (TRIPS) agreement was generated in consultation with only a very few multinational corporations. Finally, governance can vary by the overarching norms or principles that guide it (Avant and Westerwinter). Many have claimed that current governance reflects liberal norms and principles, for better or for worse.

Similarly, not all networks are the same. Network theory is a set of tools analysts use to describe network attributes and those variables that cause or are affected by them. Network theory distinguishes among networks according to three fundamental principles.

First is the distribution of ties. Which nodes are part of the network and what is the pattern of relationships among nodes? A network can be centralized, with one node in a central place linked to many others; flat, with all nodes more or less equally connected; or broken into several parts, with some nodes more connected with one part than others. Also, the ties among nodes in a network can be dense or sparse. Commonsensical references to networks often assume that they are flat and dense and that this leads to effective collective action.

Second, network theory understands relationships as conduits for the flow of material and 
nonmaterial resources, such as money, weapons, or information. Thus, the position of particular actors is another important variable. Whether actors are central or peripheral and whether they are brokers between otherwise unconnected others or part of densely connected clusters have significant implications for the distribution of material and nonmaterial resources within a network.

Finally, networks can vary by the quality of ties between nodes. What makes a node a node or what draws particular actors into a network has implications for how particular nodes, and the network as a whole, act.

Embedded in each of the ways networks can vary are questions about power. Because network theory focuses specifically on relationships, though, it leads us to highlight the idea that many forms of power are inherently relational. Your power may depend, in part, on something that you have and can take with you (such as a gun or money, for instance). But much of how you manage to get someone to do what they otherwise might not depends on how others think about and relate to you. Take police, for example. Their power rests not only in their weapons but also in people's belief that they are upholding laws that benefit everyone. In situations where police act in ways that undermine that perception, they also undermine a component of their power-and thus their ability to generate order. The riots that broke out in Los Angeles after the Rodney King beating are one example. Focusing on and developing this relational view of power is one of the key contributions of this project. It leads to what we call "the new power politics."

\section{The New Power Politics and Governance Outcomes}

Many analyses of security see security issues as distinct. Because of the stakes involved in security and the way security issues often rally "us" against "them," traditional analysts expect states to play greater roles around security issues and security issues to exhibit less cooperation-or effective governance - than one might see around economic or other issues.

The analyses in this workshop found more effective governance than one might expect in some issues. Effective governance was often the result of the centrality of traditionally powerful states. Hafner-Burton and Montgomery found that effective military alliances were often associated with one central actor. Eilstrup-Sangiovanni also found that the development of a transgovernmental network to combat nuclear proliferation resulted from the central position of the United States in its development.

In other issues cooperation was found to be a product of traditionally less powerful states' holding central or brokerage positions, as with the Swiss position vis-à-vis the regulation of military and security services (Avant). By virtue of their central position among governments and also with businesses and civil society organizations, the Swiss were able to create a network to establish rules for private security providers. By pulling in powerful states like the United States and the United Kingdom, who were willing to require participation in the rules established by this network, the Swiss began a process that generated both rules and enforcement of them.

Analyses for this workshop also found powerful roles for nonstate actors. Nonstate actors with authority based in economic capacity, expertise, or principles were found to be able to use these to develop connections that helped them achieve more effective governance in line with their goals. DeBeers' central position enhanced its economic power to shape the initial public-private scheme for governing "conflict diamonds" in the Kimberley Process. In the process, NGOs such as Global Witness and Partnership Africa Canada developed ties that allowed them to shape a 
stiffer verification scheme (and thus more effective governance) than some states would have liked (Westerwinter). Similarly, those anxious to develop a norm that states would make amends with civilians they harmed during military operations pursued a strategy of linking with important hubs in the human security network to legitimize their claims (Carpenter).

Beyond these general challenges to traditional assumptions, the workshop papers also suggest several important and counterintuitive tendencies.

Players that are seen as weak on the grounds of their relative economic or military power may nonetheless have significant influence on governance outcomes by virtue of their network position. The Swiss appear stronger in several analyses than one might expect. It appears that their commitment to neutrality leads them to connect with many different actors and often leads them to more central roles and brokerage roles, both of which enhance their influence.

\section{HOW CAN NONSTATE ACTORS AFFECT BEHAVIOR?}

1. Problem Solving: Nonstate actors can increase their power vis-à-vis a network of stakeholders by identifying a governance problem and implementing a successful solution. For example, Bower shows that some key actors pushing for a landmine ban treaty who were able to achieve their preferences during the negotiation phase were better positioned to shape the outcome in its subsequent phases.

2. Cross-Network Clout: By leveraging power in one network, nonstate actors can gain position in another. Haufler, for instance, examines the overlapping relationships among different cross-network actors in the natural resource industry and how those relationships affect actors in other networks.

3. Position Leverage: Through structural positions, nonstate actors can influence and socialize others in their network (Carpenter, Westerwinter, Avant).

a. This can be used to effectively deter conflict, as in the case of democratic IO networks and conflict resolution (Hafner-Burton and Montgomery).

b. Through connections to powerful states' preferences and authority claims, nonstate actors can influence the direction of governance. The US small arms industry's influence on the global arms industry by means of privileged government connections is one example (Avant).

4. Interpersonal or Informal Influence: Personal ties matter; strong interpersonal ties to states can lead states, even powerful ones, to overemphasize the strategic value of particular nonstate actors.

The structure of one network can have implications for behavior in another. Terrorist networks that are more centralized and hierarchical as nodes are also likely to act violently toward the other nodes around them (Heger, Jung, and Wong). 
Using one type of power can have consequences for other types of power an actor can use. Using coercion, for instance, may undermine the deference others show to an actor on the basis of some principles or cause nodes to break their ties with that actor in ways that diminish network position. Using institutional roles, knowledge, or principles to generate influence can enhance deference to an actor and thus improve their relations with others in ways that could augment their network position. Stacy Goddard demonstrates this in her comparative analysis of "revisionist" powers. Similar patterns are demonstrated by the United States in its decision to foster interdiction of nuclear materials in the PSI (Eilstrup-Sangiovanni) as well as by the variety of actors paticipating in efforts to counter piracy (Percy).

Power rooted in violence or economic capacity alone may be useful for pursuing less complex governance tasks or forestalling action; more complex tasks or generating new collective action is more likely when prospective governors root their action in expertise, principles, and relations. Thus leveraging various power sources in combined strategies can generate greater influence over governance processes. This is demonstrated by US behavior over time in efforts to influence small arms and military and security services (Avant), as well as efforts to counter money laundering (Jakobi).

Actors can improve their network position by constructing linkages using their institutional role, expertise, and commitment to principles. This is demonstrated by NGOs (Carpenter), strategic elites in Georgia (Cooley and Nexon), corporate actors (Haufler), and the Swiss government (Avant).

Identifying a governance problem can generate connections among nodes. Though our primary focus was on the impact of networks on governance, a governance goal can sometimes solidify network connections as demonstrated by the anti-land mine advocates (Bower) and the network combatting piracy (Percy).

\section{NOTES}

1 Deborah D. Avant, Martha Finnemore, and Susan K. Sell, Who Governs the Globe?, Cambridge University Press, 2010): p. 365-367

2 Barry Buzan, “New Patterns of Global Security in the Twenty-First Century," International Affairs (Royal Institute of International Affairs 1944-), Vol. 67, No. 3 (1991), p. 431-451 


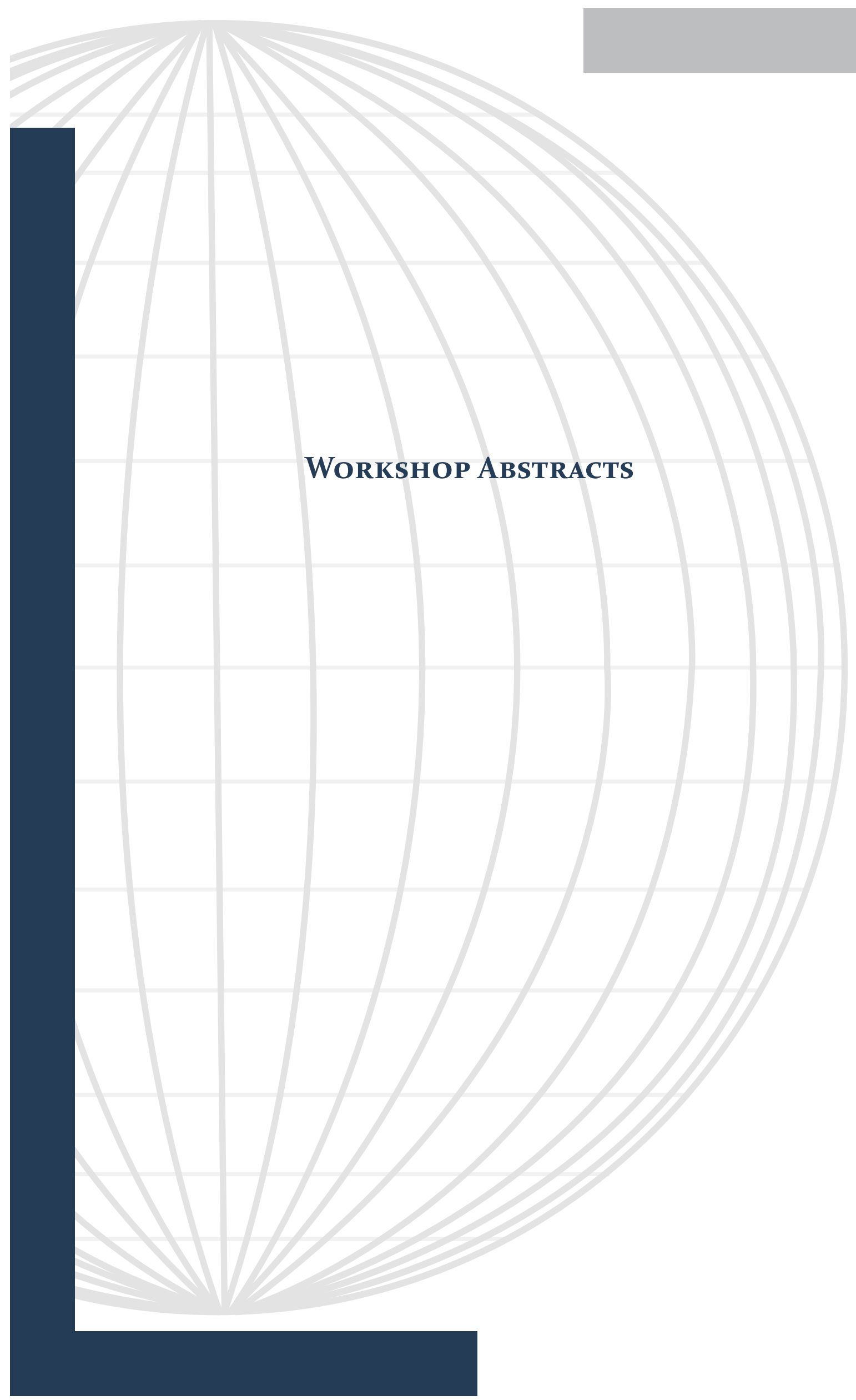

8 A ONE EARTH FUTURE FOUNDATION CONFERENCE PAPER 


\section{The New Power Politics: Introduction}

Deborah Avant, University of Denver, Deborah.Avant@du.edu

Oliver Westerwinter, European University Institute/University of St. Gallen, Oliver.Westerwinter@ eui.eu

New forms of governance constituted by different mixtures of state and nonstate actors are important venues for governing contemporary global security. In this paper, we outline three mechanisms prominent in network theories: the distribution of ties in a network, the relative position of different nodes, and the quality of interactions among nodes. We then sketch three general ways in which security governance varies: its relative effectiveness, whom it serves, and what principles inform it. Network mechanisms constitute our general independent variables and governance our dependent variables, but we are also attentive to the recursive effects of governance on networks. The logic by which network mechanisms should impact security governance depends on a relational view of power, which we introduce and then analyze how it limits and interacts with more traditional notions of power. We end by describing the other contributions to this project.

\section{Centrality in Transnational Governance: How Networks of International Institutions Affect State Behavior}

Emilie M. Hafner-Burton, University of California-San Diego, ehafner@ucsd.edu

Alexander H. Montgomery, Reed College, ahm@reed.edu

In this article, we argue that network centrality approaches can illuminate power processes affecting the principles on which governance rests and whom governance serves. We illustrate our argument by replicating two important papers on socialization through democratic international organizations and domination through alliance hierarchies. We demonstrate that using network conceptualizations and measurements of these processes allows for better connections between theory and empirics, more precise hypothesis testing, improved models, and more robust results. We find that socialization by democratic IOs is more important than dispute resolution mechanisms in preventing conflict and that domination through hierarchical alliance structures occurs throughout the entire international alliance system.

\section{Netting the Empire: US Roles in Governing Small Arms and Military and Security Services}

Deborah Avant, University of Denver, Deborah.Avant@du.edu

How to think about the US role in governing small arms and military and security services has been the center of debates about the characterization of contemporary global politics. Though the tendency has been to argue over which role is most accurate, network theory leads us to expect that whom the United States interacts with affects what role it plays and what governance outcomes are produced. Looking at the networks of US government officials vis-à-vis small arms and military and security services demonstrates very different patterns. In one, connections with 
domestic interest groups led the United States to interact with other states and intergovernmental organizations based on sovereign authority to frustrate governance. In the other, connections with a transnational group of stakeholders led the United States to interact with a broader array of state, substate, and nonstate intermediaries on the basis of a wider variety of authority claims to enhance governance. Comparison of the two reveals different influences on US goals, different uses of power by the United States, and different governance outcomes. These cases show that while the United States is a key player in global politics, theories of hegemony cannot explain US preferences. Forming connections to shape US preferences and authority claims is an important avenue for otherwise weaker players to influence the direction of transnational governance. Also, while traditional sources of power alone can be useful for frustrating governance, they work best in a supporting part linked to knowledge, principles, and network partners for generating governance.

\section{"We Are All Georgians Now": Symbolic Capital, Trust, and Authority Under Hierarchy}

Alexander Cooley, Barnard College, acooley@barnard.edu

Daniel Nexon, Georgetown University, dhn2@georgetown.edu

The new hierarchy studies pioneered by David Lake posit that subordinate states strike bargains with patrons that cede some of their sovereignty in exchange for security guarantees and deference to the patron's authority. This paper challenges some of these insights on international hierarchy and authority by exploring how the regimes of subordinate states can strategically manipulate networks of personal ties with a patron to consolidate their own domestic political standing within the patron's decision-making structures. At the same time, we show how these newly constructed personal ties between regimes actually can reduce the authority and capacity of the patron to control the client and result in "reverse socialization" where the patron adopts the values, preferences, and strategic frames of the weaker client. Our case study focuses on post-Rose Revolution Georgia and the forging of close personal relationships between Tbilisi and members of the Bush administration that affected whose governance goals influenced US action. Bush administration officials came to exaggerate the strategic importance of the small post-Soviet state, while the United States proved unable to constrain the actions of the Saakashvili regime as it initiated conflict with Russia over South Ossetia in August 2008.

\section{Bargaining in Networks: Network Structure, Informational Power, and the Politics of Blood Diamonds}

Oliver Westerwinter, European University Institute/University of St. Gallen, Oliver.Westerwinter@ eui.eu

This paper examines how states and organizations use their positions in informal communication networks to achieve favorable outcomes in global politics. More often than not governance in institutions in which states, firms, and NGOs work together to govern the adverse consequences of global corporate conduct serves the interests of some while leaving others aggrieved. However, the actors that successfully shape governance outcomes are often not those that conventional power-oriented approaches focused on the distribution of material or institutional benefits lead us 
to expect. In this paper, I argue that power based on central positions in informal communication networks is a critical source of leverage in transnational tripartite negotiations over policy choices and implementation. Especially in a context characterized by informal institutions and low transparency, the informational and strategic advantages derived from central network positions are an effective means of influence. States and organizations that occupy central or brokerage positions have access to and control over the flow of strategically valuable information. This enables them to craft better bargaining strategies and achieve favorable agreements. I illustrate these dynamics with a case study of the Kimberley Process, a public-private governance arrangement in which states, the diamond industry, and human rights NGOs collaborate to prevent profits from the global diamond trade fuelling civil wars in Africa. The case demonstrates that success in influencing the outcomes of public-private governance often hinges on actors' connections with others and their position in informal communication networks. It also shows that negotiation strategies making use of network power are particularly useful for generating new collective action.

\section{Corporate Power, Networked Governance, and Conflict}

Virginia Haufler, University of Maryland, vhaufler@umd.edu

One of the key actors in contemporary networked governance is the business community, which is both a partner in governance initiatives and their target. Corporations wield significant material power, of course, but they also derive power from their relationships - both among themselves and with other actors. This power based in relationships is particularly important for how firms participate in networked forms of governance-governance that is typically designed to restrict the options open to corporations, i.e., put constraints on economic power. One of the most dynamic arenas for networked governance is the transnational regulation of the natural resource sector as a means to reduce violent conflict. In this paper, I look at sectoral networks (commodity chains) and policy networks as based in different sources of power-material, information, and principles. The relationships among firms within these two networks, particularly at the boundaries where these overlap, influence the evolution of networked forms of governance. This paper elaborates on how corporate relationships in different networks confer power, and how that power influences the effectiveness of governance, with evidence drawn from the conflict minerals issue area.

\section{Network Relations and Human Security Norm Development: Agenda-Setting and Agenda-Vetting Around Collateral Damage Control}

Charli Carpenter, University of Massachusetts-Amherst, charli.carpenter@gmail.com

Creating new issues is a crucial step in the governance process. Why do advocacy networks promote certain issues and not others? Existing studies of issue selection within networks locate the source of variation in the attributes of actors or issues, or the wider environment in which advocates operate. Little attention is given to how relations among activist organizations themselves affect the creation and survival of issues. In this paper, I recast the case literature on advocacy campaigns to describe the ways in which network structure matters to shape the content and success of emerging normative ideas in advocacy networks. Network structure matters in two ways: (1) by shaping the relative influence of organizations over the network agenda, and (2) by shaping the preferences of 
those organizations as they construct their assessments of candidate issues. I then illustrate these dynamics through a case study of a new norm campaign: the campaign to make amends to civilians harmed in lawful military operations. The "Making Amends Campaign" shows how the success of norm entrepreneurs hinges on their ability to attract allies from powerful network "hubs" in the issue area most closely associated with the concept they are advocating, and how "gatekeepers"" willingness to adopt new issues onto their agenda is also mediated by gatekeepers' perceptions of relational ties - between actors, between issues, and between issue areas.

\section{Networking for the Ban: Network Structure, Social Power, and the Movement to Ban Antipersonnel Mines}

Adam Bower, European University Institute, Adam.Bower@eui.eu

The ban on antipersonnel mines is rightly regarded as a major humanitarian achievement, as it constitutes the first global prohibition of a weapon that was in extensive contemporary use. Scholars have previously shown how an alliance of transnational civil society and "like-minded" states achieved a legally binding ban through the use of persuasion and social pressure. Yet these studies have failed to account for the structural sources of this agency - why certain ideas won out in the face of alternatives supported by powerful actors like the United States. In this paper I argue that the position of certain key actors as hubs within the wider mine ban movement provided them with disproportionate influence in reshaping the policy agenda concerning antipersonnel mines based in part on their promise in accomplishing particular governance tasks. I first map the key actors and ties within the mine ban network and illustrate the impact of network processes in two distinct phases: the negotiation of the Mine Ban Treaty and its subsequent implementation. I then demonstrate that the network adapted as it moved from advocating for the treaty's creation to promoting its use by establishing permanent oversight and management structures and adding a dedicated Implementation Support Unit. This change in purpose and structure was paralleled by a strategic shift among hubs, as certain actors have increased their relative importance while others have decreased in stature.

\section{Structures for Actors: United States' Networking in a New Security Environment}

Anja P. Jakobi, Peace Research Institute Frankfurt, jakobi@hsfk.de

This article analyzes the United States' use of networking to achieve preferable outcomes in global governance. I first outline how power is executed in social relations, and on which kind of authority it can draw. I then develop two different concepts: power in networks refers to the internal governance of a network, the way actors relate to each other, and how interests can be realized in this cooperation. The power of networks refers to a network as governance instrument that regulates a specific issue area. Combining these two concepts enables "institutional entrepreneurship," a strategic activity to cause wide-ranging change consistent with one's preferences. This process is typical of actors that need a high degree of cooperation to realize their own interests, and networks help to socialize rules that are initially the preference of single actors alone. Empirically, the article traces this process in the United States' strategy with respect to anti-money laundering. The United States first developed a small policy network in which it held crucial positions and influenced main 
policy outcomes. In a second step, this network expanded and became the focal point for global governance in fighting money laundering worldwide. Combining quantitative and qualitative analyses, the article thus shows how the development of global regulations and activities on this issue has been closely related to American foreign policy and how networking was an effective tool through which the United States could pursue its interests in shaping transnational governance.

\section{Power and Purpose in Transgovernmental Networks: Insights from the Global Nonproliferation Regime}

Mette Eilstrup-Sangiovanni, University of Cambridge, mer29@cam.ac.uk

Although transnational governance networks (TGNs) have received growing attention, scholars have rarely used the tools of social network analysis (SNA) to analyze the structural composition of such networks. I seek to fill this gap by using SNA to scrutinize a small number of TGNs focused on preventing or reversing proliferation of weapons of mass destruction and related technologies. Based on direct links among substate officials and operating without close control or supervision by cabinets or chief executives, TGNs comprise a specific form of organization whose main characteristics include loose ties, distributed decision making, informality, and the absence of any central, rule-based authority or control. I uncover three general findings about the nature and role of power in TGNs. First, the formation of TGNs is associated with concentrations of material and institutional power. Network structures based on loose ties and informal relations tend to arise around powerful actors whose preponderant resources make them likely recipients of in-links from other actors, and who can provide a focal point for cooperation as well as supply (informal) dispute resolution. Second, the distribution of ties in TGNs is a function of exogenous power differentials. Actors who are considered prominent outside a TGN also tend to enjoy a central position within the network. Rather than merely reflect exogenous power inequalities, however, network ties tend to augment such inequalities. Third, TGNs redistribute power within states. TGNs operate at substate level and tend to enjoy low political visibility, thereby reducing the potential for domestic veto players to constrain their behavior. I evaluate my argument against evidence from four TGNs focused on nonproliferation: the Missile Technology Control Regime, the Proliferation Security Initiative, and the Cooperative Threat Reduction program. I show that these networks are structurally different from a formal legalized regime such as the nonproliferation treaty, and that the particular relational structure of these TGNs enhances the freedom of action of strong players such as the United States, thereby augmenting their power and influence.

\section{Counter-Piracy Networks, Power, and Governance}

Sarah Percy, University of Western Australia, sarah.percy@uwa.edu.au

This paper examines the network of international navies conducting counter-piracy missions off the coast of Somalia. The anti-piracy network provides an unusual form of military cooperation, with nations as diverse as Iran, the United States, India, China, and Britain all working together through a variety of modes to control the pirate problem. This unlikely form of networked security governance has resulted in part from the unique nature of Somali piracy. The network is itself more 
flat than is typical in other forms of multinational military cooperation, which has taken a distinctly hierarchical form. I make three arguments about security governance networks on the basis of the counter-piracy network. First, I argue that countering Somali piracy would be impossible without this network. Second, I argue that military cooperation need not always take a hierarchical form, and that in this case it would be impossible to have cooperation unless the network were flat and informal. Third, I argue that in networks that require a high degree of cooperative behavior, such as this one, nodes are unlikely to manipulate their positions to enhance power because doing so would jeopardize the network's overall goals.

\section{Governance and Security: How Organizational Structure Shapes Violence}

Lindsay L. Heger, One Earth Future Foundation, lheger@oneearthfuture.org

Danielle F. Jung, Emory University, dfjung@gmail.com

Wendy H. Wong, University of Toronto, wendyhwong@gmail.com

Though most scholarship has focused on violence originating from the state, violence originating from nonstate actors comprises an increasingly significant threat in contemporary global politics. We have only begun to understand the organization of relationships within nonstate groups but know from research on states that the type and structure of states matter in predicting stateperpetrated violence. Motivated by these findings, we argue the organizational relationships that characterize violent nonstate actors affect the character of violent outcomes. In this article, we theorize that more centralized terrorist groups produce different violent output than less centralized groups. Because centralized connections create advantages in transmission of information, functional differentiation, command and control structures, and accountability, they should be capable of more threatening forms of violence. We use one measure of centralization, the provision of social services, to distinguish each group's centralization based on the logic that centralized groups are more likely to provide social services than less centralized groups. This group-level measure captures the range of functions the organization is able to provide, the scale of provision, as well as its proficiency in provision, thereby reflecting differences in organizational centralization. We then use this measure to analyze each organization's violence profile, including targeting, tactical choices, and the frequency of violent attacks. We analyze data for 400 terrorist groups over thirty years to test our hypotheses. We find that just as internal governance structures affect the external behavior of states, so too do internal governance structures affect the behavior of nonstate actors.

\section{Help or Hindrance? The Role of Humanitarian Military Interventions in Human Security NGO Operations}

Amanda Murdie, University of Missouri, murdiea@missouri.edu

Sam R. Bell, Kansas State University, sbell3@ksu.edu 
Patricia Blocksome, Kansas State University, pjb@ksu.edu

Kevin Brown, Kansas State University, kbrown22@ksu.edu

How do humanitarian military interventions influence the ability of NGOs to do their work? Previous work has found that the joint presence of military and NGO actors is essential for the fulfillment of the most complex human security tasks after humanitarian disasters, like improvements in government human rights performance and economic development. NGOs were better able to fulfill their human security objectives when humanitarian military interventions were present, arguably because military interveners provide logistical support that aids in collaboration between various humanitarian actors, including NGOs, and because military interveners provide security. In this paper, we use network analysis methods to examine the process through which military interventions improve the ability of NGOs to connect to each other and econometric methods to examine the ways in which interventions influence the violence NGOs face from domestic actors. Using a dataset of over 2,500 human security organizations involved in states with a history of humanitarian disasters, we find that human security NGOs involved in countries where there is a humanitarian military intervention benefit in terms of their network ties to other NGOs.

\section{The Small Worlds of al-Muhajiroun: Network Structure, Collective Action, and Power in a Dark Transnational Advocacy Network}

Michael Kenney, University of Pittsburgh, mkenney@pitt.edu

Stephen Coulthart

Michael Martin

In recent years, the British government has sought to counter a transnational advocacy network believed to be radicalizing young men and women into an extremist, and violent, interpretation of Islam. This paper explores how this network, al-Muhajiroun, has continued to engage in high-risk activism despite being outlawed by the British government. The paper employs a mixed-methods case study of al-Muhajiroun and its banned spin-off groups. We use formal network analysis and qualitative content analysis to understand how this political network changed in response to British policy. We examine node- and network-level measures at three different time periods, corresponding to major events in al-Muhajiroun's development and changes in British policy. The network maintained itself in the face of the British ban by shifting from a centralized, or scale-free, structure to a more decentralized, or small world, structure.

\section{Illicit Arms for Africa: The Prominence of the Former Soviet Bloc}

David Kinsella, Portland State University, kinsella@pdx.edu

Small arms and light weapons are the primary causes of death in the violent conflicts raging today. Although the small arms trade is difficult to track, and the illicit trade doubly so, a wealth of information is available. Drawing on the Illicit Arms Transfer Database, which systematizes information contained in journalistic reports on illicit small arms transfers, this paper applies 
some basic tools of social network analysis (SNA) to reveal the high profile of former Soviet bloc countries in the illicit arms trade with Africa. I set up this analysis with a discussion of the features of social networks that allow them to facilitate the transfer of illicit weaponry, and follow the presentation of my findings with some explanations for the prominence of Russia and other postcommunist countries in this trade. Consistent with other papers in this symposium, my examination focuses on the importance of relationships, their quantity and quality, as providing opportunities for, and constraints on, the flow of material and social resources between the actors and locales that comprise the illicit arms trade network. I also highlight the extent to which the positions of key players may account for their power within the network and their roles in maintaining the secrecy and redundancy required for illicit trade in the face of efforts by authorities to disrupt relationships pivotal to the transfer of contraband. 
The One Earth Future Foundation was founded in 2007 with the goal of supporting research and practice in the area of peace and governance. OEF believes that a world beyond war can be achieved by the development of new and effective systems of cooperation, coordination, and decision making. We believe that business and civil society have important roles to play in filling governance gaps in partnership with states. When state, business, and civil society coordinate their efforts, they can achieve effective, equitable solutions to global problems.

As an operating foundation, we engage in research and practice that supports our overall mission. Research materials from OEF envision improved governance structures and policy options, analyze and document the performance of existing governance institutions, and provide intellectual support to the field operations of our implementation projects. Our active field projects apply our research outputs to existing governance challenges, particularly those causing threats to peace and security.

The OEF conference report series provides a synthetic review of the discussion that happens at OEF-sponsored events.

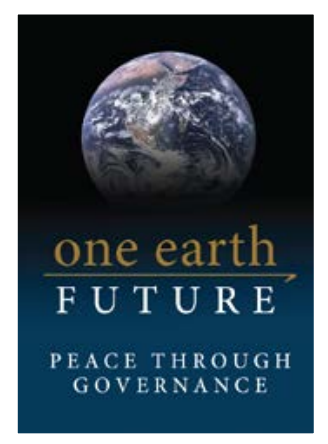

ONE EARTH FUTURE FOUNDATION

525 Zang Street, Suite $C$

Broomfield, CO 80021 USA

Ph. +1.303.533.1715 Fax +1 303.309.0386 


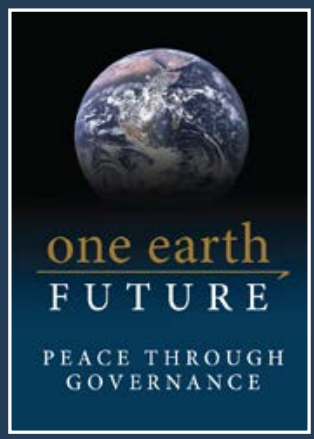

\section{ONE EARTH FUTURE FOUNDATION}

525 Zang Street, Suite C

Broomfield, CO 80021 USA

Ph. +1.303.533.1715 Fax +1 303.309.0386 